Check for updates

Cite this: RSC Adv., 2017, 7, 26532

Received 23rd February 2017 Accepted 9th May 2017

DOI: $10.1039 / \mathrm{c} 7 \mathrm{ra02286g}$

rsc.li/rsc-advances

\title{
Sequestration of orange $G$ and methylene blue from aqueous solutions using a Co(II) coordination polymer†
}

\begin{abstract}
Cressa Ria P. Fulong and Timothy R. Cook (iD *
A Co(॥) coordination polymer known for its crystalline sponge properties (CoSP) is used to sequester Orange G (OG) and methylene blue (MB) in aqueous solutions. Its ability to encapsulate the cationic MB is much greater than for OG. The CoSP material is notable for its structural transformations under different conditions (i.e. removal from solvent or immersion in alternative solvent systems) giving rise to both 3D and 2D networks. Herein, we study the activated semi-amorphous Co sponge (a-CoSP) as a host in aqueous solutions and find that guest uptake results in increased crystallinity as evidenced by powder X-ray diffraction (PXRD). Reactivation releases some dye due to decomposition of the coordination polymer however, the solubility of the building blocks in solution enables the reconstruction of the sponge.
\end{abstract}

\section{Introduction}

Organic dyes are a class of pollutants that are commonly found in industrial wastewater due to their wide application as colorants for textiles, papers, food, and as imaging agents. ${ }^{1}$ There are more than 100000 commercially available organic dyes of various sizes, colors, and ionicity that are being produced annually. ${ }^{2}$ Aside from their toxicities and carcinogenicities, these colored effluents may interfere with the absorption and reflection of light in water, thereby affecting biological processes in natural systems. ${ }^{3}$ Many dyes are stable and nonbiodegradable in water. As a consequence, strict environmental regulations are currently imposed by national and international agencies for the manufacture and use of these organic dyes. ${ }^{4}$

The most common methods for the removal of organic dyes in wastewater is through physical, chemical, and/or biological methods. ${ }^{5,6}$ Each method has its own advantages and disadvantages; however, physical removal via adsorption is generally considered as the most rapid way to reduce dye concentration in water. ${ }^{4}$ Nanomaterials have been extensively studied, not only as adsorbents for the removal of organic dyes in water, but also as photo-catalysts for degradation. ${ }^{711}$ These materials are very efficient in organic dye removal and degradation but suffer from agglomeration and post-separation difficulties. ${ }^{2}$

Department of Chemistry, University at Buffalo, The State University of New York, Buffalo, New York 14260, USA. E-mail: trcook@buffalo.edu

$\dagger$ Electronic supplementary information (ESI) available: Experimental details of dye uptake and release; UV-vis spectra; TGA data; PXRD patterns; FT-IR spectra; XPS spectra. See DOI: 10.1039/c7ra02286g
Over the past two decades metal-organic frameworks (MOFs) have attracted attention for their application in the adsorption and photo-catalytic degradation of organic dyes.,12 One of the practical challenges in the use of MOFs as adsorbents for organic dyes is their water instability. ${ }^{13}$ Several studies have demonstrated that frameworks with $\mathrm{N}$-atom donors are more water stable than those with O-atom donors, such as

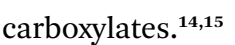

With this in mind, we hypothesized that the $\left[\left(\mathrm{Co}(\mathrm{NCS})_{2}\right)_{3}\right.$ $\left.(\mathrm{TPT})_{4}\right] \cdot 25\left(o-\mathrm{C}_{6} \mathrm{H}_{4} \mathrm{Cl}_{2}\right) \cdot 5(\mathrm{MeOH}) \quad(\mathrm{TPT}=2,4,6$-tris(4-pyridyl)1,3,5-triazine) "cobalt sponge" coordination polymer (CoSP) previously reported by Fujita and co-workers ${ }^{16}$ may serve as a stable host for the absorption of organic dyes in water. The host/guest chemistry of this material has been demonstrated using a variety of guests including tetrathiafulvalene, ${ }^{16}$ fullerenes ${ }^{16}$ titanocene, ${ }^{16}$ aldehydes,${ }^{17}$ and cyclohexanone. ${ }^{18}$ This ability of MOFs to accommodate guests in crystalline form was

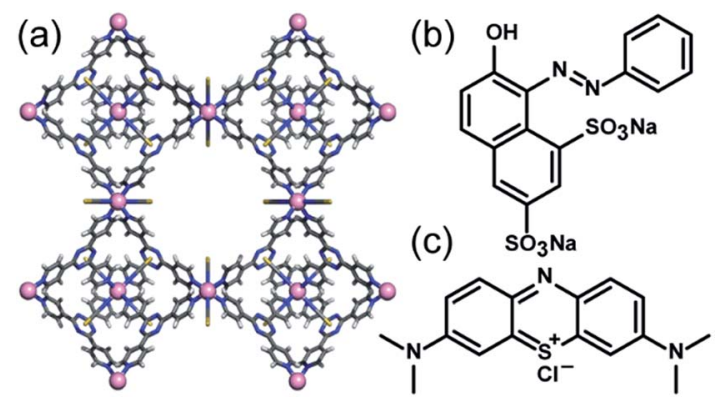

Fig. 1 (a) Structure of $\operatorname{CoSP}(\mathrm{C}=$ gray, $\mathrm{N}=$ blue, $\mathrm{Co}=$ pink, $\mathrm{S}=$ yellow, CCDC no. 766604, † ref. 17); organic dye pollutants orange $G(b)$ and methylene blue (c). 
known as the crystalline sponge method. The structure of this Co sponge (Fig. 1a) was initially solved in the cubic space group $F m \overline{3} m$ with octahedral Co(II) centres with two trans NCS ligands and four pyridyl donors originating from four unique TPT ligands. Murugesu and co-workers recently reported microcrystals of CoSP belonging to the trigonal space group $R 3 \mathrm{~m}$ with the same overall structure as the framework reported by Fujita and co-workers, with different solvents of crystallization. ${ }^{19}$ It was observed that the orange crystals (i-CoSP; inactive form) transformed to a green semi-amorphous material (a-CoSP; activated form) upon removal from the mother liquor, attributed to the removal of solvent and loss of crystallinity of the framework. In this activated form, guest molecules can occupy the void spaces that once housed solvents of crystallization. A second transformation to a $2 \mathrm{D}$ network was also observed. ${ }^{19}$

\section{Results and discussion}

In this work, the crystalline sponge method for the absorption of an anionic dye, orange G (OG, Fig. 1b), and a cationic dye, methylene blue (MB, Fig. 1c) was investigated. CoSP crystals were synthesized in $1: 1(\mathrm{v} / \mathrm{v}) o-\mathrm{C}_{6} \mathrm{H}_{4} \mathrm{Cl}_{2}: \mathrm{MeOH}$ as published in the literature. ${ }^{16}$ Crystals still immersed in the mother liquor were combined with solutions containing OG or MB. The combined solutions were slowly evaporated to concentrate the dyes. ${ }^{20}$ The encapsulation of OG and MB into i-CoSP were observed within a few minutes, as shown in videos S1 and S2 (ESI $\dagger$ ). The encapsulation process is more distinct with $\mathrm{MB}$, wherein the orange crystals become light green (Fig. 2a and b). Although single crystals were obtained that readily reveal the metalorganic backbone, the location of encapsulated dyes could not be determined due to disorder. The tendency of guests to display static disorder was also observed by Fujita and co-workers. ${ }^{20}$

We were interested in determining if the loss of crystallinity of CoSP had an effect on the competency of the material for host/guest chemistry, particularly for organic dyes. The crystalline sponge method is predicated on maintaining single crystal quality, thus the host/guest chemistry of the semi-

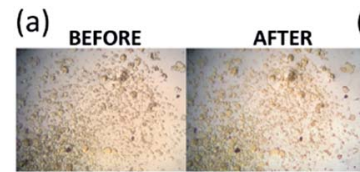

(c)

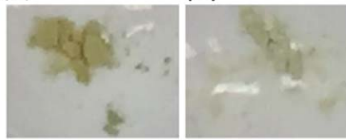

(g)

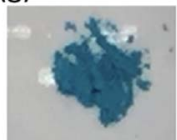

(h) (b) BEFORE

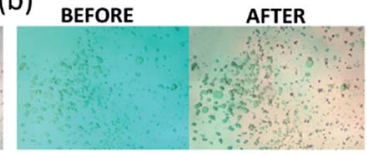

(e)

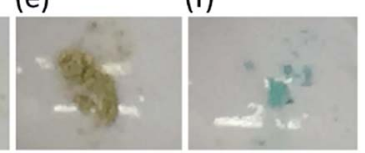

(j) (i)

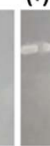

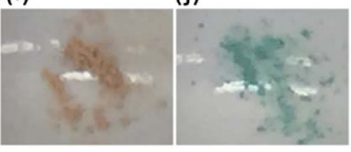

Fig. 2 Images of CoSP crystals before and after absorption of (a) OG and (b) MB; (c) i-CoSP powder, (d) after adsorption of water, (e) OG, and (f) MB; and (g) a-CoSP powder, (h) after adsorption of water, (i) OG, and (j) $M B$. amorphous state has not been explored. For these experiments, microcrystalline CoSP was prepared at a $100 \mathrm{mg}$ scale. ${ }^{17}$

Upon synthesis, orange microcrystals were obtained. Filtration of these microcrystals delivers a fine orange powder (iCoSP, Fig. 2c). Air-drying or activation at $120{ }^{\circ} \mathrm{C}$ under vacuum effects a change to a green powder (activated, Fig. $2 \mathrm{~g}$ ).

PXRD patterns of i-CoSP (Fig. 3a) and a-CoSP (Fig. 3d) are very similar, and also match the pattern of the green semiamorphous material reported by Murugesu and co-workers. SEM provides further evidence that a-CoSP represents a conversion to the semi-amorphous state. The facets observed of the crystallites of a-CoSP are softened but still observable in the activated material (Fig. S1 $\dagger$ ). Our results are consistent with the observations of Murugesu, wherein the transformation into a green powder occurs upon the loss of solvent molecules that occupy voids in the coordination polymer.

\section{Thermogravimetric analysis}

TGA curves (Fig. 4) showed three significant mass-loss steps for these materials. The first step at $150{ }^{\circ} \mathrm{C}$ is consistent with the removal of $\mathrm{H}_{2} \mathrm{O}, \mathrm{MeOH}$, and $o-\mathrm{C}_{6} \mathrm{H}_{4} \mathrm{Cl}_{2}$. The mass-loss at $350{ }^{\circ} \mathrm{C}$ has previously been attributed to the decomposition of the TPT ligands. ${ }^{21}$

The final step at $450{ }^{\circ} \mathrm{C}$ corresponds to the decomposition of the $\mathrm{SCN}^{-}$ligands. ${ }^{19}$ Both i-CoSP and a-CoSP showed mass loss as the samples were heated to $150{ }^{\circ} \mathrm{C}$; however, the inactivated sample underwent a larger percent change, consistent with the loss of a greater amount of solvent molecules relative to the activated cage, in which many solvents had already been removed. As the temperature exceeded $\sim 160{ }^{\circ} \mathrm{C}$, a steep drop in $\%$ weight was observed attributed to a loss of $o-\mathrm{C}_{6} \mathrm{H}_{4} \mathrm{Cl}_{2}$.

\section{Fourier transform infrared spectroscopy}

Fourier transform infrared spectroscopy (FT-IR) analysis further supported the hypothesis of solvent removal upon activation

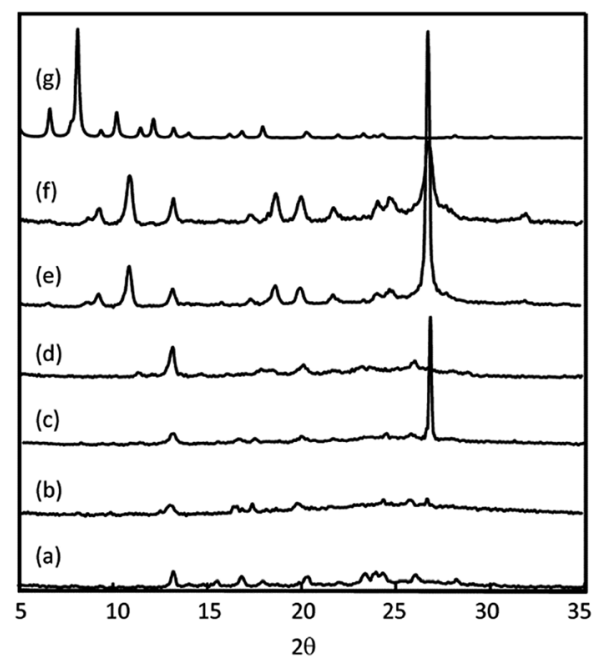

Fig. 3 PXRD patterns of (a) i-CoSP; (b) i-CoSP $+\mathrm{H}_{2} \mathrm{O}$; (c) i-CoSP + aqueous OG; (d) a-CoSP; (e) a-CoSP $+\mathrm{H}_{2} \mathrm{O}$; (f) a-CoSP + aqueous OG; and $(\mathrm{g})$ simulated. 


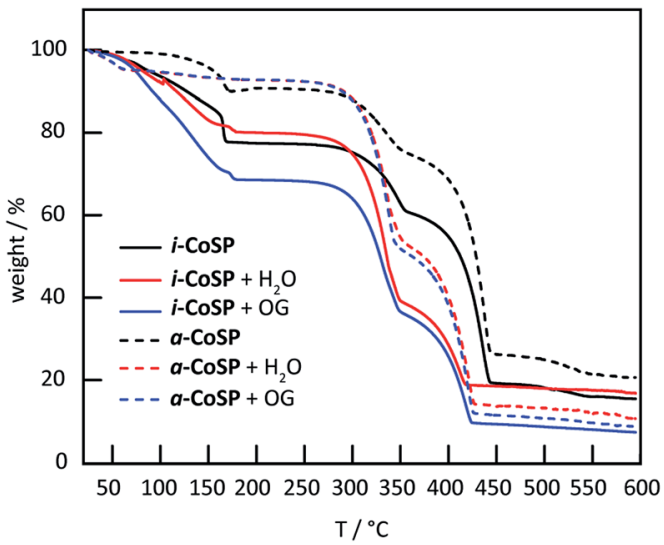

Fig. 4 TGA curves of inactive and activated Co sponge powder before and after uptake of water and OG.

without a total loss of the framework. The FT-IR spectra of both the inactive and activated sponges (Fig. 5) showed characteristic $\mathrm{CN}$ stretching bands at $<2100 \mathrm{~cm}^{-1}$ that correspond to the $\mathrm{SCN}^{-}$ ligands. ${ }^{22,23}$

The broad band at $\sim 3350 \mathrm{~cm}^{-1}$ typically observed for $\mathrm{OH}$ stretching is absent in both materials. However, stretching (3030 and $\left.1600 \mathrm{~cm}^{-1}\right)$ and bending (690-900 $\mathrm{cm}^{-1}$ ) bands for the aromatic rings and stretching $\left(800-550 \mathrm{~cm}^{-1}\right)$ bands for $\mathrm{C}-\mathrm{Cl}$ are observed in i-CoSP. These bands are attenuated in a-CoSP, as expected if the $o-\mathrm{C}_{6} \mathrm{H}_{4} \mathrm{Cl}_{2}$ are removed during activation.

\section{Dye update studies}

Both inactive and activated powders were tested for the uptake of OG and MB. $\sim 10 \mathrm{mg}$ of material were added to $40 \mu \mathrm{M}\left(18 \mathrm{mg} \mathrm{L}^{-1}\right)$ OG and $10 \mu \mathrm{M}\left(4 \mathrm{mg} \mathrm{L}^{-1}\right) \mathrm{MB}$ aqueous solutions. These mixtures

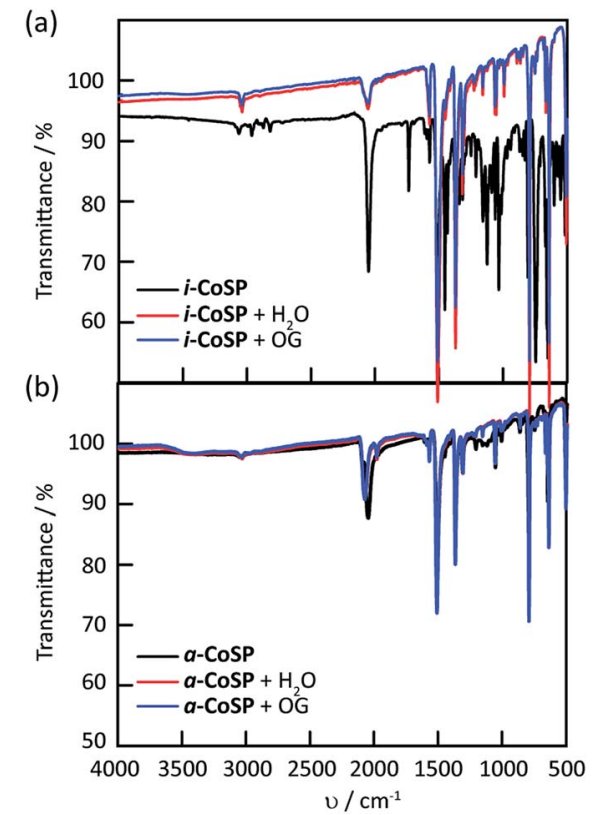

Fig. 5 FT-IR spectra of (a) inactive and (b) activated Co sponge powder before and after uptake of water and OG. were stirred for $30 \mathrm{~min}$ at room temperature. The solutions were analysed over the course of 2 days. The electronic absorption spectra showed an $8 \%$ decrease in OG concentration for i-CoSP and a 55\% decrease for a-CoSP (Fig. 6a and b). i-CoSP removes a significant amount of $\mathrm{MB}$ (70\% decrease in $\mathrm{MB}$ concentration). The use of a-CoSP drops the dye concentration even further, by 93\% (Fig. 6c and d). Fig. 7 summarizes the absorption capacities $(q \mathrm{e})$ of $10 \mathrm{mg}$ inactive and activated powders for OG and MB. In all cases, dye uptake is completed within $24 \mathrm{~h}$, resulting in capacities of $0.4 \mathrm{mg} \mathrm{g}^{-1}$ for i-CoSP + OG; $4.6 \mathrm{mg} \mathrm{g}^{-1}$ for a-CoSP + OG; $1.4 \mathrm{mg} \mathrm{g}^{-1}$ for i-CoSP + MB; and $1.8 \mathrm{mg} \mathrm{g}^{-1}$ for a-CoSP + MB. These values indicate that activation is necessary to maximize the uptake capacity of the Co sponge for both anionic and cationic dyes.

\section{Absorption kinetics}

The kinetics of the absorption processes were investigated using a series of absorption experiments (Fig. S2a and $\left.\mathrm{b}_{\dagger} \dagger\right) .{ }^{14}$ The absorption capacities of MB into both i-CoSP and a-CoSP were plotted against time and the data were fit with first-order kinetics, providing rate constants $\left(k_{1}\right)$ of 0.09 and $0.20 \mathrm{~s}^{-1}$, respectively (Table $\mathrm{S} 1 \dagger$ ), indicating that the activated material more rapidly removes the dye from solution. In both cases, the maximum absorption capacity is achieved within 40 minutes. Due to the settling time required for scatter-free spectra, OG uptake was measured every 20 minutes and all spectral changes were complete in the blind-time following initial mixing. Since all uptake occurred within the first 20 minutes, it is clear that OG is sequestered faster than MB.

The ability to remove guests from such systems is attractive insomuch that the material may then be reused to sequester additional molecules. ${ }^{24}$ The equilibrium constant associated with the host/guest complexation plays a significant role in the ease with which guests may be removed. The kinetics of the release of $\mathrm{OG}$ and $\mathrm{MB}$ were investigated (Fig. S2c, d and Table $\mathrm{S} 1 \dagger)$. Using a first-order kinetic model, $k_{-1}$ for dye release was found to be $0.04 \mathrm{~s}^{-1}$ for OG. For MB, small spectral changes
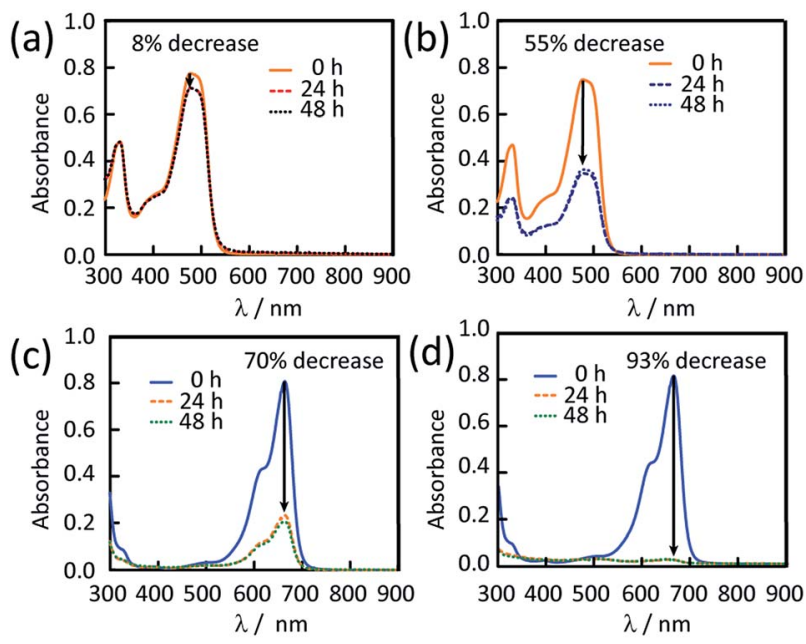

Fig. 6 UV-vis spectra for the dye absorption of i-CoSP (left) and aCoSP (right) with OG (top) and MB (bottom). 


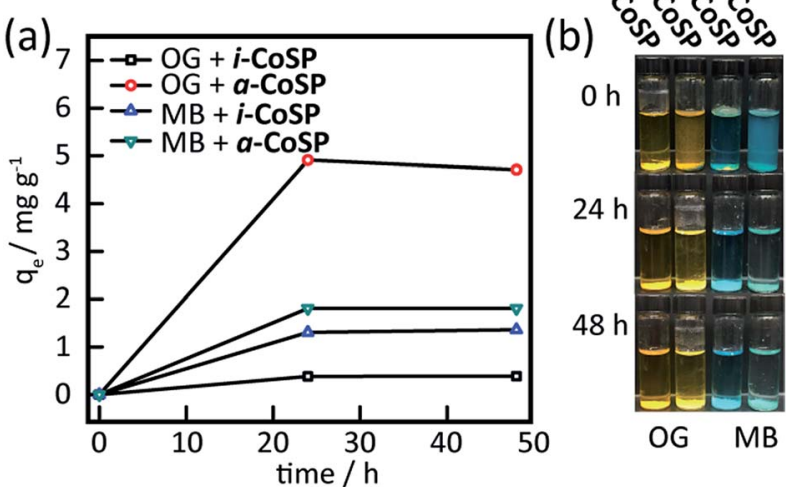

Fig. 7 (a) Absorption capacity ( $q_{\mathrm{e}}$ in $\mathrm{mg}$ dye per $\mathrm{g}$ Co sponge) of inactive and activated Co sponge powder for $O G$ and $M B$ and (b) images of $O G$ and $M B$ solutions after 0,24 , and $48 \mathrm{~h}$ of adding inactive and activated Co sponge powder

were observed when the material was reintroduced to solution; however, these changes are consistent with a small amount of network dissolving and thus releasing the guest, rather than release from the intact CoSP. The lack of any significant absorption from free MB obviates a determination of $k_{-1}$ and indicates that $\mathrm{MB}$ binds much more strongly to the material. ${ }^{25}$

The water stabilities of i-CoSP and a-CoSP were determined using UV-vis spectroscopy. CoSP has a characteristic band at $500 \mathrm{~nm}$ that is used to monitor stability, though the material is very insoluble $(A \sim 0.02)$ over the course of 48 hours this band is largely unchanged, with evidence for a slight amount of further dissolution (Fig. S3a and $\mathrm{b}_{\dagger}$ ). The shoulder at $350 \mathrm{~nm}$ is due to absorption by the encapsulated $o-\mathrm{C}_{6} \mathrm{H}_{4} \mathrm{Cl}_{2}$ in the inactive material. $^{26}$

\section{X-ray methods}

We noted an additional crystal transformation behaviour over the course of our studies. When the semi-amorphous activated powder is exposed to either water or solutions of dyes in water, the PXRD patterns indicate that crystallinity is increased relative to the initial material (Fig. 3). The increase in crystallinity occurs with restoration of solvent molecules back into the coordination network as evidenced by the growth of characteristic bands in the FT-IR spectra (Fig. 5). The presence of encapsulated water is observed as a broad band at $3350 \mathrm{~cm}^{-1}$ in the FT-IR spectra (Fig. 5b). Images of the powders, shown in Fig. 2, illustrate that the activated material (Fig. 2g) undergoes a significant colour change when suspended in water (Fig. 2h), or when exposed to the dyes (Fig. $2 \mathrm{i}$ and $\mathrm{j}$ ). Similar changes occur for the inactivated material, however given the orange nature of initial state (Fig. 2c), the changes are subtler. Upon reactivation (r-CoSP), i.e. activated material is exposed to solvent or dye, then reheated at $120{ }^{\circ} \mathrm{C}$ for $10 \mathrm{~h}$, solvent removal is very minimal based on the TGA curves (Fig. S4 $\dagger$ ) and the PXRD patterns do not show significant differences to those of the singly-activated materials (Fig. S5f and h†). This is consistent with a slow dye release rate wherein dyes largely remain and prevent reuptake. However, r-CoSP is still water stable as demonstrated by the minimal decrease in absorption at $500 \mathrm{~nm}$ compared to the activated sponge (Fig. S3c $\dagger$ ).

X-ray photoelectron spectroscopy (XPS) has been used to provide information about the composition of extended networks and the oxidation states any metal ions present in a sample. ${ }^{27} \mathrm{XPS}$ was conducted on a-CoSP, a-CoSP $+\mathrm{H}_{2} \mathrm{O}$, a-CoSP + OG, and aCoSP + MB. In all four samples, survey spectra showed the presence of $\mathrm{Co}(\mathrm{II}), \mathrm{N}, \mathrm{C}, \mathrm{S}$, and $\mathrm{O}$. The first four components are directly part of the CoSP network, whereas the oxygen originates from $\mathrm{H}_{2} \mathrm{O}$ or from the dyes, when present. As shown in Fig. S7$\mathrm{S} 10, \uparrow$ high-resolution peaks corresponding to $\mathrm{C}$ 1s indicate a significant amount of non-oxygenated carbon $(\sim 284.8 \mathrm{eV})$ with some C-N contributions at higher energy $(\sim 286.9 \mathrm{eV}) .{ }^{28}$ In all of the samples, the Co $2 \mathrm{p}$ binding energies show $2 \mathrm{p}_{1 / 2}$ and $2 \mathrm{p}_{3 / 2}$ peaks at $\sim 797.2 \mathrm{eV}$ and $\sim 781.2 \mathrm{eV}$, respectively. These peaks have satellite bands shifted to higher energy by $\sim 6 \mathrm{eV}$, diagnostic of $\mathrm{Co}(\mathrm{II}) .{ }^{29,30}$ Although the bands corresponding to all five elements (Co, N, C, S, O) are present in all samples, the intensities and high resolution fits differ due to the compositional changes associated with activation and guest uptake.

\section{Experimental}

\section{Materials and methods}

All reagents and solvents were reagent grade and used as received without further purification. 2,4,6-Tris(4-pyridyl)-1,3,5triazine (TPT), Orange $\mathrm{G}(\mathrm{OG})$, and $o$-dichlorobenzene (o$\mathrm{C}_{6} \mathrm{H}_{4} \mathrm{Cl}_{2}$ ) were purchased from TCI Chemicals. Methylene blue (MB) was purchased from Acros Organics. Cobalt(II) thiocyanate $\left(\mathrm{Co}(\mathrm{NCS})_{2}\right)$ was purchased from Alfa Aesar. Methanol (MeOH) was purchased from Fisher Chemical. Deionized water was used in all absorption, release, and stability experiments. All UV-vis spectra were acquired from an Agilent Cary 8454 UV-vis Diode Array system with a $10 \mathrm{~mm}$ rectangular quartz cuvette. Blank spectra with deionized water were acquired in between runs. All powder X-ray diffraction (PXRD) patterns were collected from a Rigaku Ultima IV system with inert atmosphere attachment and heated sample chamber equipped with $\mathrm{Cu}$ source $(0.15418 \mathrm{~nm} \mathrm{~K} \alpha)$ and operated at $1.76 \mathrm{~kW}$ power $(40 \mathrm{kV}, 44 \mathrm{~mA})$. Diffraction patterns were measured within $2 \theta$ range of 5 to $35^{\circ}$ at a rate of $1^{\circ} \mathrm{min}^{-1}$. Thermogravimetric analysis (TGA) curves were measured from a TA Instruments DSC SDT Q600 instrument at a heating rate of $5^{\circ} \min ^{-1}$ from $25-600{ }^{\circ} \mathrm{C}$ under constant flow of nitrogen $\left(100 \mathrm{~mL} \mathrm{~min}^{-1}\right)$. Fourier transforminfrared (FT-IR) spectra were acquired from a Perkin Elmer 1760 FT-IR spectrometer equipped with horizontal attenuated total reflectance (HATR) from 4000 to $500 \mathrm{~cm}^{-1}$ wavenumbers. Field Emission Scanning Microscope (FESEM) images were captured using a Hitachi SU70 FESEM with Oxford Energydispersive X-ray Spectrometer (EDS). All X-ray photoelectron spectroscopy (XPS) spectra were measured using a Physical Electronics Phi Versaprobe 5000 with $\mathrm{Al} \mathrm{K \alpha}$ source instrument.

\section{Syntheses}

Synthesis of crystalline Co sponge (CoSP). Co sponge crystals, $\left\{\left[\left(\mathrm{Co}(\mathrm{NCS})_{2}\right)_{3}(\mathrm{TPT})_{4}\right] \cdot 25\left(o-\mathrm{C}_{6} \mathrm{H}_{4} \mathrm{Cl}_{2}\right) \cdot 5(\mathrm{MeOH})\right\}_{n}$, were grown 
following a published procedure. ${ }^{16}$ A solution of TPT $(6.3 \mathrm{mg}, 20$ $\mu \mathrm{mol})$ in $5 \mathrm{~mL}$ of $1: 4(\mathrm{v} / \mathrm{v}) \mathrm{MeOH}: o-\mathrm{C}_{6} \mathrm{H}_{4} \mathrm{Cl}_{2}$ was placed in a dram vial. Carefully layered on top of this is a $1 \mathrm{~mL} \mathrm{MeOH}$ solution of $\mathrm{Co}(\mathrm{NCS})_{2}(7.0 \mathrm{mg}, 40 \mu \mathrm{mol})$. This solution was left to stand for 7 days or until orange crystals are formed on the glass surface.

Synthesis of inactive Co sponge powder (i-CoSP). $\left\{\left[\left(\mathrm{Co}(\mathrm{NCS})_{2}\right)_{3}\left(\kappa^{3}-\mathrm{TPT}\right)_{4}\right] \cdot a\left(\mathrm{H}_{2} \mathrm{O}\right) \cdot b(\mathrm{MeOH})\right\}_{n} \quad(\mathbf{i}-\mathrm{CoSP}),{ }^{19} \quad$ was synthesized following a published procedure. ${ }^{17}$ A solution of TPT (315 mg, $1.0 \mathrm{mmol})$ in $250 \mathrm{~mL}$ of $1: 4(\mathrm{v} / \mathrm{v}) \mathrm{MeOH}: o^{-}$ $\mathrm{C}_{6} \mathrm{H}_{4} \mathrm{Cl}_{2}$ was placed in a $500 \mathrm{~mL}$ round bottom flask and stirred at $600 \mathrm{rpm}$. A $50 \mathrm{~mL} \mathrm{MeOH}$ solution of $\mathrm{Co}(\mathrm{NCS})_{2}(350 \mathrm{mg}, 2.0$ $\mathrm{mmol}$ ) was added to the TPT solution. The mixture was stirred for $15 \mathrm{~min}$ and left to stand for $2 \mathrm{~h}$. i-CoSP was collected by filtration and washed with $o-\mathrm{C}_{6} \mathrm{H}_{4} \mathrm{Cl}_{2}$.

Activated Co sponge powder (a-CoSP). $\left\{\left[\left(\mathrm{Co}(\mathrm{NCS})_{2}\right)_{3}\left(\kappa^{0-3}-\right.\right.\right.$ $\left.\left.\mathrm{TPT})_{4}\right] \cdot c\left(\mathrm{H}_{2} \mathrm{O}\right)\right\}_{n}{ }^{19}$ (a-CoSP) was prepared by pre-treating the synthesized powder before use. ${ }^{31}$ This involves heating the synthesized i-CoSP at $120^{\circ} \mathrm{C}$ under vacuum for at least $10 \mathrm{~h}$.

\section{Conclusions}

In summary, we have established that CoSP MOF first reported by Fujita and co-workers is capable of serving as a host for two organic dyes, OG and MB. The absorption capability of the sponge is greatly enhanced by removal of trapped solvents by activating with heat at $120^{\circ} \mathrm{C}$ for $10 \mathrm{~h}$. The activation accelerates the transformation to a semi-amorphous material previously discovered by Murugesu and co-workers. We have shown that this activation altered the crystallinity of the MOF but does not hinder host/guest chemistry. Removal of trapped solvents frees up void spaces for dye encapsulation. CoSP does not degrade in aqueous solution and remains capable of dye adsorption even in a semi-amorphous state. The crystallinity of the material was greatly affected by this host/guest chemistry. The semiamorphous activated form regained crystallinity when immersed in water or solutions of dyes. Although the kinetics of uptake were faster for OG, the cationic MB bound much more tightly to the framework, with minimal reversibility.

\section{Acknowledgements}

TRC thanks the University at Buffalo and State University of New York Research Foundation for support. The authors thank Dr Joshua Wallace for assistance with XPS measurements.

\section{Notes and references}

1 G. Booth, H. Zollinger, K. McLaren, W. G. Sharples and A. Westwell, in Ullmann's Encyclopedia of Industrial Chemistry, Wiley-VCH Verlag GmbH \& Co. KGaA, 2000, DOI: 10.1002/14356007.a09_073.

2 C.-C. Wang, J.-R. Li, X.-L. Lv, Y.-Q. Zhang and G. Guo, Energy Environ. Sci., 2014, 7, 2831-2867.

3 W.-T. Tsai, H.-C. Hsu, T.-Y. Su, K.-Y. Lin, C.-M. Lin and T.-H. Dai, J. Hazard. Mater., 2007, 147, 1056-1062.

4 Environmental Chemistry of Dyes and Pigments, ed. A. F. Reife and H. S. Freeman, John Wiley and Sons, New York, 1996.
5 O. J. Hao, H. Kim and P.-C. Chiang, Crit. Rev. Environ. Sci. Technol., 2000, 30, 449-505.

6 Y. M. Slokar and A. Majcen Le Marechal, Dyes Pigm., 1998, 37, 335-356.

7 S. Wang, H. Sun, H. M. Ang and M. O. Tadé, Chem. Eng. J., 2013, 226, 336-347.

8 S. C. N. Tang and I. M. C. Lo, Water Res., 2013, 47, 2613-2632.

9 X. Wang, M. Zhu, H. Liu, J. Ma and F. Li, Sci. Total Environ., 2013, 449, 157-167.

10 X. Zhao, L. Lv, B. Pan, W. Zhang, S. Zhang and Q. Zhang, Chem. Eng. J., 2011, 170, 381-394.

11 D. Shuai, D. C. McCalman, J. K. Choe, J. R. Shapley, W. F. Schneider and C. J. Werth, ACS Catal., 2013, 3, 453-463.

12 E. M. Dias and C. Petit, J. Mater. Chem. A, 2015, 3, 2248422506.

13 A. Ayati, M. N. Shahrak, B. Tanhaei and M. Sillanpää, Chemosphere, 2016, 160, 30-44.

14 Z.-P. Qi, J.-M. Yang, Y.-S. Kang, F. Guo and W.-Y. Sun, Dalton Trans., 2016, 45, 8753-8759.

15 J. J. Low, A. I. Benin, P. Jakubczak, J. F. Abrahamian, S. A. Faheem and R. R. Willis, J. Am. Chem. Soc., 2009, 131, 15834-15842.

16 Y. Inokuma, T. Arai and M. Fujita, Nat. Chem., 2010, 2, 780-783. 17 S. Matsuzaki, T. Arai, K. Ikemoto, Y. Inokuma and M. Fujita, J. Am. Chem. Soc., 2014, 136, 17899-17901.

18 Y. Y. Inokuma Shota, A. Junko, A. Tatsuhiko, H. Yuki, T. Kentaro, M. Shigeki, R. Kari and F. Makoto, Nature, 2013, 495, 461-466.

19 G. Brunet, D. A. Safin, I. Korobkov, A. Cognigni and M. Murugesu, Cryst. Growth Des., 2016, 16, 4043-4050.

20 M. Hoshino, A. Khutia, H. Xing, Y. Inokuma and M. Fujita, IUCrJ, 2016, 3, 139-151.

21 M.-X. Li, Z.-X. Miao, M. Shao, S.-W. Liang and S.-R. Zhu, Inorg. Chem., 2008, 47, 4481-4489.

22 K. Nakamoto, in Infrared and Raman Spectra of Inorganic and Coordination Compounds, John Wiley \& Sons, Inc., 2008, ch. 2, pp. 149-354, DOI: 10.1002/9780470405840.

23 B. Schrader, in Infrared and Raman Spectroscopy, Wiley-VCH Verlag GmbH, 2007, pp. 711-764, DOI: 10.1002/ 9783527615438.refs.

24 S.-N. Sheng, Y. Han, B. Wang, C. Zhao, F. Yang, M.-J. Zhao, Y.-B. Xie and J.-R. Li, J. Solid State Chem., 2016, 233, 143-149.

25 M. Roushani, Z. Saedi and T. Musa beygi, J. Taiwan Inst. Chem. Eng., 2016, 66, 164-171.

26 J. G. Mattay and A. G. Griesbeck, in Photochemical Key Steps in Organic Synthesis, Wiley-VCH Verlag GmbH, 2007, pp. 261-283, DOI: 10.1002/9783527615797.ch05.

27 J. Jiang, L. Huang, X. Liu and L. Ai, ACS Appl. Mater. Interfaces, 2017, 9, 7193-7201.

28 S. Bag, K. Roy, C. S. Gopinath and C. R. Raj, ACS Appl. Mater. Interfaces, 2014, 6, 2692-2699.

29 W. Wei, W. Chen and D. G. Ivey, Chem. Mater., 2008, 20, 1941-1947.

30 S. Bennici, H. Yu, E. Obeid and A. Auroux, Int. J. Hydrogen Energy, 2011, 36, 7431-7442.

31 F.-R. Dai, D. C. Becht and Z. Wang, Chem. Commun., 2014, 50, 5385-5387. 